\title{
Balancing Boundaries: Everyday Boundary Work in Information Technology Project Management
}

\author{
Eva Maaninen-Olsson \\ Carnegie Mellon University and Uppsala University \\ emolsson@andrew.cmu.edu
}

\author{
Magnus Mähring \\ Stockholm School of Economics \\ magnus.mahring@,hhs.se
}

\begin{abstract}
This study draws upon the project and team literatures to explore how project boundaries are managed across the IT project life-cycle. A longitudinal study of a commercial automation control solutions provider was conducted. Particular emphasis was placed on the interaction between one focal project and its environment. We found that recurrent, situated boundary activities pertaining to temporal, task and team boundaries are of central importance for how a project unfolds. We argue that recent attention to organizational boundary-spanning in information systems research needs to be supplemented with a broader and richer view of the functions and significance of boundary work for IT projects, particularly in multi-project environments.
\end{abstract}

\section{Introduction}

This paper explores boundary work across the lifecycle of an information technology (IT) project, focusing on temporal, task and organizational boundaries that delimit and define the project. In spite of the wealth of research on IT projects and information systems (IS) development, limited attention has been placed on boundary work [25].

We therefore draw upon latest advances in project theorizing, as well as the boundary-spanning literature, to explore IT project management from a boundary perspective. Recent research on project organizing upsets conventional wisdom on projects as autonomous entities, by emphasizing that projects are historically and contextually embedded, interacting with their environment, and subjected to challenges to project boundaries [13, 23, 41, 44]. Consequently, projects are viewed as both autonomous and embedded [40, 43] and boundary work [40] becomes an essential project management activity. Project boundaries (temporal, task, and organizational) have to be constructed, maintained [29], guarded [12], renegotiated [40] and spanned [3, 8]. How these intertwined boundary activities play out during a project is not well understood, and the study of boundaries has the potential to shed new light on how IT projects evolve. The purpose of this paper is therefore to explore boundary work throughout the IT project life cycle.

We pursue this aim through a longitudinal study of an automation control systems solution provider, with particular focus on one turnkey customer project and its boundary activities. In the following, we discuss literature on project boundaries and IS development issues related to boundary work. We then describe our research approach and subsequently our case study. Thereafter we discuss our findings and present the study's conclusions, as well as its limitations and implications for research and practice.

\section{Background}

Within the IS field, studies that expressly focus boundary activities, such as boundary-spanning, are scarce. However, the IS literature encompasses many topics that involve boundary activities. Issues that involve spanning of organizational boundaries between groups or occupations, include user-developer interaction [5], stakeholder issues [38], change management [33] and cross-functional or crossorganizational implementation and use of information systems [22, 27, 38]. The few studies within IS that focus boundary-spanning have explored interaction between occupational and stakeholder groups in the use of intranets and knowledge management systems $[25,26]$ or studied political processes in IS development [15]. In contrast, boundary spanning studies are well-established in the team literature [3, 20] and increasingly frequent in the project organizing literature $[32,40,41]$. We therefore draw upon these research areas in our exploration of boundary activities during the IT project life-cycle.

The project literature has traditionally viewed projects as autonomous, goal-focused units achieving success by carrying out the stipulated tasks and 
delivering the specified results [10, 29, 37]. However, recent research on project organizing and temporary organizations emphasizes that projects are embedded in, and interact with, their environments $[6,13,41]$. The resulting duality of autonomy and embeddedness leads to an attachment-detachment dilemma in the management of projects $[40,43]$. As a consequence, activities that relate to boundaries, or "boundary work", become central to project theorizing [40].

Two views of project boundaries exist in the literature. Studies that focus on team effectiveness and boundary-spanning predominantly deal with organizational boundaries, such as between a unit or team and its organizational environment $[3,41]$ and/or more informal organizational boundaries that restrict the transfer and diffusion of project learning [41]. Studies aimed at developing theories on projects often take a broader view of boundaries, in which boundaries delimit the project not only organizationally but also temporally and in task $[13,29,32,40]$. In this paper, we adopt this broader view and look at activities that impact the boundaries that help constitute the project. We thus define the boundaries of a project as encompassing organizational boundaries (which define the project organization/team in relation to its environment), temporal boundaries (which define the life-span of a project) and task boundaries (which delimit the task to be executed). We also adopt the view of boundary work as an ongoing activity that delineates what "belongs" and not belongs, what is inside and outside, who is an insider and who is an outsider [16, 40].

Some prior research has described the need to open and close organizational boundaries as related to phase: temporary organizations are open in their formative stage(s) but then decouple from the environment into "planned isolation" until the point of delivery of results, project termination and knowledge dissemination [29]. In contrast, studies on projectbased organizations $[14,19]$ and cross-project knowledge transfer $[8,41]$ emphasize the importance of recurrent spanning of organizational boundaries throughout the project life-cycle.

Similarly, literature on teams, particularly within research and development and new product development, emphasize the importance of boundaryspanning activities in these contexts [2,3]. Ancona and Caldwell [3] even found comprehensive organizational boundary spanning to be considerably more important for project success than within-project efficiency and coherence. Boundary activities in this literature includes ambassadorial (representing the team to others and protecting it from interference), task coordinating (interacting with other units to achieve necessary coordination), scouting (interacting with the environment to find information about markets, technology and competition), guarding (preventing transfer of information from the project team to its environment) and knowledge sharing [3, 41].

As for temporal boundaries, it has been noted that the setting and re-setting of deadlines is a temporal form of control [47] and a delineation that is the very basis for what constitutes a project [40]. It has also been argued that pre- and (potential) post-histories shape how actors approach a project and their actions and decisions during the process [13]. When deadlines are connected to major events that are external to the project, the project also becomes delimited in relation to such events, which may also contribute to crystallizing the project's raison d'être [29].

Correspondingly, changes in the project task can be understood as something more profound than scope management: the ongoing reinterpretation and adjustment of the task, as well as deliberate and explicit changes to the task definition, constitute boundary work. [40].

It would seem that the extant literature has not systematically studied how different boundary activities pertain to different types of boundaries throughout the lifecycle of a project, or what triggers boundary work. In addition, it might prove fruitful to explore what actors are involved in boundary work according to our broader definition, in particular since previous studies found organizational boundaryspanning activities unequally distributed amongst team members $[3,20]$. Furthermore, while previous work has discussed adaptation of time and task in the face of contingencies [23], to our knowledge no systematic attempt has been made to view these adaptations as part of ongoing project boundary work.

\section{Research approach}

A longitudinal case study [21, 35] was conducted within one organization. This approach allows for the study of boundary work across time and in context [46, 48]. The selected field site was a division within a multinational engineering corporation delivering turnkey automation solutions to process industries. Within the Automation Solutions (AS) division, we focused on the business unit serving steel manufacturers (AS Steel). Full access to the field site was granted for an extended time period, which was a necessary prerequisite for the study. The field site was also assessed to be highly suitable for studying boundary activities: projects involved internal as well as external stakeholders [38], they concerned complex requirements and non-standard solutions involving advanced problem-solving activities [3], and they occurred in a multi-project environment [34]. 
At the time of the study, AS Steel had 90 employees conducting around 20 concurrent customer projects, with most employees being involved in several projects simultaneously. This setting provided for the study of project boundary work between the project and other projects, the base organization, the customer and suppliers. The AS Steel base organization, its project management practices and two specific projects were studied. The focal project in this paper, NEU, was studied from its pre-history and inception to implementation at the customer site.

During field work, semi-structured interviews and observations were conducted interchangeably [48]. In total, 49 interviews with an average duration of two to three hours were conducted. Observations included meetings as well as day-to-day work activities. Secondary data were also collected to supplement the primary data sources, to triangulate data and to control for informant bias [11, 17].

Based on our data, an extensive chronological account of events was constructed and an extensive case description was written. This was sent to the head of projects and the NEU project manager, as well as corroborated through meetings with NEU project members and other project managers.

Based on the extensive case description and the complete case study database, an iterative analysis process took place. Typical of process research, the analysis involved cycles of deduction and induction [1, 36]. In addition to shaping a coherent understanding of the project process, our analysis focused on detecting instances of boundary work and identifying central characteristics (or attributes) of boundary activities.

Three recurrent characteristics of boundary activities emerged: initiative (internal or external), stakeholders involved, and intentions. The latter included: knowledge transfer, dissemination and search; renegotiation of deliverables and time; and adjustments of project specifications. After the analysis was completed, the case description was condensed and structured in chronologically sequenced episodes, each highlighting a specific instance of boundary work. The results are presented by using the thematic concepts derived from the analysis.

\section{Boundary work in a multi-project environment}

\subsection{Empirical context}

The integrated hardware and software automation solutions delivered by AS Steel included tailored control systems software, electrical motors, generators, low voltage equipment, electronic instrumentation and power electronics. The base organization of AS Steel was structured in departments. Three departments supplied projects with different types of expertise: Project Management, Engineering (hardware, software, R\&D) and Installation. AS Steel also had several departments not involved in project work: Accounting, Logistics, and Sales and Marketing. Project personnel regularly worked on several projects simultaneously and were physically located by functional area of expertise. Interaction with peers took place on a daily basis, but intensity varied with individual preferences.

All projects were conducted towards external customers. Most projects concerned upgrades or replacement of control systems in existing production environments, while a few concerned completely new plants. While AS Steel used a set of standardized product and software components, these regularly had to be adapted and configured to fit the specific production environments at customer sites. Projects were initiated after a sales process had been completed and a contract signed. Typical project phases where: Start-up, Basic design, Detail design, Factory Acceptance Test (FAT) and Installation.

The Start-up phase consisted of a formal hand over of the contract from the Sales Department to the project team and included discussions of the contract details and required activities. in the Basic Design and Detail Design phases, engineering personnel designed the system and specified software and hardware components. The purpose of the Factory Acceptance Test was to ensure that system functionality was in accordance with the specifications. During the FAT the customer was asked to participate, and thus had the possibility to comment on and/or approve necessary final changes. The Installation phase consisted of shutting down an existing automation system, implementing the new system, and receiving customer approval of the new system.

The studied project, NEU, had a budget of 200000 USD. The customer site had a unique arrangement in that the motors controlling production equipment were hydraulically controlled, not electrically, which required additional development activities. AS Steel personnel was not knowledgeable about hydraulically driven motors, and only a handful of steel mills were using this technology. The customer also demanded to influence design work, making the use off-the-shelf solutions difficult.

The delivery specifications were set two years before the NEU project started, because the customer hard ordered two separate deliveries; one for the conventional section of the steel mill, and one for the section using hydraulic motors. Project specifications were at this time preliminary, but still important as a blueprint of customer needs. The specifications were 
put together by the account manager and experts on the different contractual components.

\subsection{Boundary work in the NEU project}

In this section we focus on key episodes of boundary work in and around the NEU project. The episodes are arranged chronologically.

4.2.1. Episode 1: Initiation and startup - handover of contract. After the contract was officially signed it was handed over from the sales department to the project manager. The main interaction taking place at this time was between the account manager and the project manager. Formal interaction included receiving relevant documents (contract, meeting minutes etc); informal interaction in personal meetings served to transfer crucial knowledge about the customer and the deliverables:

"By having informal meetings I get a better understanding of the customer, what has been sold and what is new in this contract, compared to other contracts. I also get information on what problems and challenges the first of the two projects had. (Project Manager)

Other significant contacts for the project manager included the project manager from the prior project with the same customer and other project managers within AS Steel.

"I got in contact with a colleague, and asked about some of the documents that he uses when he starts up a project. He is a really experienced project manager, and by getting these documents I could speed up the start-up process. "(Project Manager)

Knowledge about the customer was also transferred from the prior project with the same customer into the NEU project through the lead engineer in NEU, who had also participated in the prior project. He brought knowledge about customer needs and the customer site into the NEU project.

"I don't know what we would have done without [the lead engineer] Mike. He knows who to contact and he knows about the customer's site. Those things are crucial to get a grip on early in the project". (External consultant)

However, there were still considerable uncertainties that had to be resolved during the course of the project:

"The customer doesn't know what he has bought, I as a sales person don't know what we really have sold, and engineering doesn't know what to construct." (Account Manager)

They did know when to deliver, however: from the beginning of the NEU project, it was known that the new automation control system had to be implemented during a planned shut-down of the customer plant for maintenance.

4.2.2. Episode 2: Initiation and startup - the unknown expert group. During our interviews, it became apparent that project members were unaware of the existence of an expert group during the contract bid phase, which had gained knowledge about the customer and customer needs. When asking the lead engineer about the project team's contacts with the members of the previous expert group, he answered:

"I didn't even know that there was an expert group".

One explanation for this lack of knowledge sharing between the expert group and the project group can be seen in the extended time span from the contract process to the start-up of the NEU project. Expert groups were generally active during the pre-project phase, and were not supposed or expected to be part of the project. They perceived the actual project as a closed entity where they did not have any responsibilities. When their task was accomplished, they turned to the next task, helping account managers with the next bid. For the project team, the situation was similar; the sales phase was not part of the project and, hence, team members did not consider the advantages of searching for information from the expert group during the start-up phase.

4.2.3. Episode 3: Design phase - participation in business development meetings. During the design phase of the NEU project, a Business Development (BD) program was initiated within AS Steel. A workshop series was initiated for each functional area to improve knowledge sharing between projects and thereby systematically improve work practices and project outcomes. However, the NEU project members to a varying degree found themselves "trapped" between the project and the BD program. The project manager, like his peers in other projects, chose to participate in the $\mathrm{BD}$ workshops to a relatively high extent, whereas the engineers in NEU and in general mostly refrained from going to workshops.

"Should I work with the project or should I go to the Business Development program? We always have things going on, and we are supposed to deliver. The customers cannot wait." (Hardware engineer)

The goal of being on time thus contributed to the team's focus on the immediate project task, instead of a long term goal that was positive for the whole organization. Another reason for not participating in the BD workshops was that the NEU project was considered unique. The NEU project was based on an old automation system technology, which was to be replaced by a newly developed system in subsequently 
projects. In addition, technology for hydraulic motors was not considered applicable to future projects. For both these reasons, knowledge transfer between the NEU project and its organizational environment was considered largely a waste of time.

4.2.4. Episode 4: Design phase - modifications to project specifications. When the project team started work on the basic design they relied on the specifications agreed upon during the sales phase. These specifications had been set in agreement with customer requirements. The hardware and software engineers started to work on drawings and specifications, and purchase of necessary material, which included pulpits, cabinets etc.

When a rough basic systems design had been produced, members of the project team traveled to the customer site to inspect the facilities intended for the cabinets housing electronic and electrical equipment. Upon inspection the crew realized that the room was too small to fit all the cabinets required for the automation system. Intensive discussions followed within the project and between the project and the customer. Drawings had to be changed and re-drawn, the number of cabinets was reduced and a wall at the customer site was eventually torn down in order to create enough space for the cabinets.

4.2.5. Episode 5: Design phase - on-site simulations. During the Detail Design phase, overall system functionality was finalized. As engineers worked to freeze the "spec", however, new required changes to specifications were continually discovered as project members continued to learn about the customer site and received customer feedback on system design.

In order to minimize the risk for surprises during implementation, the customer requested production simulations to be run on site, which the project approved to and the senior R\&D engineer designed. The tests were off-line "dry runs", which means that "rolling pairs" (which flatten hot metal into sheets) were rotated without heated material coming through. Signals and control information were tested at the same time. To make the tests work, the project team and the customer had to collaborate on setting operational parameters for the equipment. The test results provided feedback on both strengths and weaknesses of the control system, leading to modifications of the new system and then, iteratively, to new simulation tests. The R\&D engineer also relied on an engineering colleague to provide input for problem solving and setting of system parameters. This interaction occurred informally as needed throughout the period of the simulation activities.
4.2.6. Episode 6: Test phase - the crashing core software module. Some time before the factory acceptance test (FAT), the core software module crashed during program execution. This was a critical issue for both the project and the since there was now a risk that the rolling mill process would stop suddenly during operation. A joint effort to solve the problem was instantly initiated and engineers immediately asked their peers in the AS Steel, particularly those specialized in the core products, for help. A solution was worked out and implemented. However, shortly thereafter the same problem reoccurred. Through their interaction with engineers working on other projects the project team had found out that these problems had occurred in other projects as well and they decided to seek help from the software supplier and request an extended, in-depth trial and error search.

"We attempted to have experts from a internal supplier to help out. Unfortunately they were already engaged in other projects, and we did not have time to wait for them. By the time they said that they could help us, we decided to turn down their offer." (Lead Engineer)

The NEU project team thus proceeded with problem solving activities within the team. Ultimately, the unstable software module was replaced with another module that was simpler but had the essential functionality. In addition to the time issue, a frequently stated reason for solving the problem internally was that this would make the project team more knowledgeable about the delivered system, which would benefit installation and implementation.

4.2.7. Episode 7: Test phase - final factory acceptance test. Observations of the final FAT showed the importance of having the customer participating in the tests. Personnel from the customer provided the project team with input on problems and possible solutions that still needed to be attended to:

"It is great to have the customer here. It is better that issues come up during this phase of the project than at the end of it. Misunderstandings between us are easier to solve now compared to when we have delivered the system. (Lead Engineer)

During the FAT the project members and the customer engaged in intense dialogue; everything from the size of the touch buttons on the control screen to how the new system would facilitate and improve the quality of production. Adjustments to system functionality were discussed and agreed upon after assessment by the customer and the project team. Customer needs were based on the existing system functionality and customer representatives wanted as few changes as possible in the user interface.

"It has to be a compromise between how the operators run their mill, without us having to deviate 
too much from our standards. We need to find a way to meet both needs, which requires a lot of discussions between us and the customer." (Hardware engineer)

4.2.8. Project outcome. The FAT was followed by transport of equipment, system installation and initiation of mill operations with the new system. At the beginning of this phase most project members started to conclude their involvement in NEU and moved on to new projects. Only three project members remained on the project to make sure everything was running at the customer's site. During this phase customer input remained crucial to project work:

"I have told the Lead Engineer that the guys from the customer need to be here during this phase. If not, everything will take much longer. They know their mill better than we do". (Installation Engineer)

At the time of the official ending of the project no discussions took place about lessons learnt: team members where already fully engaged in other projects, and most team members still were of the opinion that the specificities of the technologies employed in the project implied that no useful knowledge could be transferred to future projects.

\section{Discussion}

In the following we discuss the findings from the NEU case. We first address how temporal, task and organizational boundary work played out during the project. Thereafter, we discuss how boundary work pertaining to different boundaries is interrelated. Finally, we discuss how IS development research can benefit from employing a boundary work perspective.

\subsection{Temporal Boundary Activities}

Consistent with earlier theorizing on projects [29, 40], the setting of time boundaries was found to be of crucial importance in the definition of the NEU project as well as in project execution. In addition to the obvious function of defining the start and end of the project, the start time was closely related to the setting up of the project team and the delimitation of the project task. This was manifested in the almost ritualized handover from the sales department to the project. At the time of the handover, the project organization formally came into existence. Furthermore, the project task was also delimited by the handover: the handover functioned as a temporal boundary object [47] and thus every work task before the handover was the responsibility of the sales department, while everything happening after the handover was the responsibility of the project [29]. This construction of clear-cut boundaries, delineating before and after, sales activities and project tasks, and sales department and project team, can be seen as typical of project management practice [13]. With our focus on boundary work, we can see that the simultaneous construction of three different types of boundaries together help create "the project" as a separate entity executing a separate process.

As soon as boundaries had been shaped boundary spanning activities were initiated. Most of those activities concerned knowledge transfer between sales and project, i.e. organizational boundary spanning, which will be discussed further below. There were, however, also instances of boundary spanning across both time and team boundaries. For example, the activities of the former expert group were decoupled from the NEU project because of the distance in time between the expert group's work and the formal start of the project. Thus, there was a lack of boundary spanning activities across time and team boundaries. As the project leader became aware of the prior existence of an expert group, he initiated scouting activities to remedy this shortcoming and assimilate knowledge gained by that group. This can be seen as reaching out from the project team but also as an attempt to span a temporal boundary, trying to grasp knowledge developed at that earlier time [40, 47].

The end bracket of the time boundary was similarly important in the organization of project work. It impacted other boundary activities, such as decisions on initiating or refraining from organizational boundary spanning, evident for example in the choice to turn down the offer from a supplier to help solve software problems and in the limited involvement in the BD workshops, Our case also illustrates how external events impact how the significance and perceptions of the end time bracket [40]: since the customer was going to shut down the plant at a certain time for maintenance purposes, the time window for implementing the new automation system was fixed and limited, which had a galvanizing effect on the project team and help push the project team towards prioritizing local results and local learning over organization-wide development activities.

In our case time boundaries were not renegotiated. There are many accounts in the literature of projects that experience repeated renegotiation of the end time bracket [e.g., 18]. In addition, there are also accounts of projects for which the timestamp of the starting point is retrospectively renegotiated [30].

In sum, this discussion points to a number of ways in which temporal boundary work is essential in project management, in particular how the setting of temporal boundaries impacts project activities, including task and temporal boundary work 


\subsection{Task boundary activities}

The customer contract provided a clear general description of what the project was to deliver to the customer. Within this specification, however, a number of design choices had to be made and a number of changes were necessary to solve design problems as they arose. Problem solving related to the task often led to task coordination and technical scouting activities, discussed below.

Several standard procedures and routines were integrated into the project task and thus supported, guided, and restricted project work [13], as did management's emphasis on reuse of standard solutions. Another important aspect of how the project team defined their task was the team members' common view that the NEU project had little to learn from other projects and little to contribute to other projects. This project framing [31], based on the fact that NEU was the only project working with a particular, "old" technology at the customer site, further demarcated the project from its environment and contributed to reduced interaction with the environment (i.e., limited team/organizational boundary spanning).

In the case of the crashing core software module, the NEU project team had the option of having the internal software supplier deal with the problem and deliver a solution. This choice would have implied a change of task boundaries (and team boundary spanning in the form of task coordination). Instead, the team chose to solve the problem themselves. The stated reasons for the choice were time pressure (a consequence of the set temporal boundaries) and the preference for knowing every detail of the delivered system at the point of installation. In a sense, the latter reason can be seen as a consequence of how the task was framed and the resulting view of the project as different from other projects and irrelevant for organizational learning because of technologies used.

\subsection{Organizational boundary activities}

The appointment of team members for the NEU project followed the standard procedures in AS Steel and the location of team members also followed the standard practice of co-location by function/expertise rather than by team. In spite of physical location, the project members quickly formed a view of themselves as a team. Furthermore, as described above, they defined their task as requiring little interaction with the environment.

Still, boundary spanning between the NEU project and the environment occurred frequently throughout the project process. Task coordination activities [3] took place towards the AS Steel organization, towards other parts of the corporation, and with the customer. Technical scouting [3] also took place towards the AS Steel base organization and other parts of organization, although the attempt to engage the internal software supplier in trouble-shooting was not followed through. In many cases, ambiguities and problems pertaining to overall and detail design of the automation system were addressed by tapping on expertise outside the project team. The project manager repeatedly turned to the responsible sales person to request additional input on what the customer needs were and what had, in detail, been agreed with the customer. The project manager also turned to a senior colleague to gain access to informal "best practices", particularly in the initial project phase. Engineers turned to their peers outside the NEU project to solve everyday design problems. Most project members interacted with the customer on various occasions.

On the other hand, there were also instances where the project closed its boundaries and refrained from organizational boundary spanning when this was requested from the host organization. This was the case with the business development effort which involved a structured process to facilitate organizational learning between projects and improved standard procedures residing in the host organization that new projects could draw upon.

We conclude that task ambiguity as well as technical contingencies triggers organizational boundary spanning to the host organization and the customer. Similarly, changes in customer needs and task requirements also lead to organizational boundary spanning aiming to provide sufficient guidance for resolving these issues. We can also notice that some boundary work was triggered by the customer (e.g., the user interface of control displays) while other instances were on the initiative of the project team (e.g., the simulation runs used to test the reliability of the automation control system).

Our observations on organizational boundary spanning indicate some interesting differences to observations of boundary spanning of R\&D labs and new product development (NPD) teams in prior studies $[3,20,45]$. These studies on R\&D and NPD teams found that boundary spanning activities were to the major part conducted by relatively few of the team members and some studies indicate that different actors assumed different boundary-spanning roles [3]. In contrast, the NEU case exhibits a broader distribution of boundary spanning amongst team members, perhaps because it involves direct customer interaction and installation of a turnkey solution on a customer site. This characteristic of the project means that the specific and detailed "fit" of the project output to one particular context was in focus, whereas R\&D and 
NPD projects normally produce designs and prototypes of artifacts intended to cater to the needs of a large number of future customers.

\subsection{Intertwining of boundary activities}

The above discussion shows that different types of project boundaries have joint or combined consequences and that boundary activities concerning one type of boundary are impacted by prior or concurrent activities pertaining to other boundaries. For example, setting of time boundaries coincided with and served to reinforce task and team boundaries at the handover from the sales department to the project team; and the project team's definition of the task contributed to reducing the willingness and extent of team boundary spanning.

The discussion also shows that boundary work related to time, task and team boundaries are crucial to day-to-day project activities and that choices made about spanning and closing of boundaries have substantial impacts on the project trajectory.

\subsection{Lessons for IS Development Research from a Boundary Work Perspective}

Compared to a traditional IS development (ISD) perspective, the boundary work perspective provides a quite different view of what happens in an IT project. Project-internal activities (design, programming) fade into the background, while activities that trigger or constitute boundary work are highlighted. Important ISD tasks, such as user-developer interaction [5] and requirements definition [22] take on a more fluid nature where interaction and change happens as needed. This approach to requirements work has been discussed by Bergman et al. [7], who stress that systems requirements emerge from a heterogeneous process of social interaction.

In spite of the contractual arrangement underlying the studied project, which according to studies on outsourcing arrangements [4, 9] would be associated with a well-specified, fixed definition of deliverables, the specifications of the studied system kept changing until the end of the project. This phenomenon has previously been identified in the subcontracting of $R \& D$ projects [42] suggesting a similarity between IT projects and $R \& D$ efforts.

\section{Conclusions and implications}

Although recent contributions to project theorizing has highlighted the importance of historical and contextual embeddedness of projects [13] and team boundary spanning, and some authors point to boundary issues as an important area of study [40, 43], relatively few empirical studies of project boundary work exist. The first contribution of this paper thus lies in offering an in-depth, longitudinal study that moves towards a broader view of boundary work. Our study has aimed to fill a gap in the literature by looking at project boundaries and how project members and other actors engage in setting, guarding, renegotiating and spanning boundaries. By turning our attention from the inside activities of projects to the boundary activities, interesting perspectives open up. The study sheds light on the everyday dynamics of projects: rather than shifting in the manner of punctuated equilibrium [39], the studied project had a trajectory that was subject to potential and actual adjustments on an almost continuous basis. Consequently, the study highlights that the balancing of project boundaries is a critical aspect of project management [40], and that this activity is carried out not only by the appointed project manager, but by a large number of project team members in their day-to-day project work. Our study also found that activities pertaining to different types of boundaries sometimes coincide, influence each other, and intertwine.

Another interesting finding is the framing of the project. The definition of the task contributes to the isolation of the project from its context. This isolation is not a given when the project starts, but rather a result of the framing taking place. Research on knowledge barriers between project/teams [28, 34, 41] has previously not included this conscious framing and consequent isolation of the project. We also found that events inside and outside both the project itself and the host organization can trigger boundary activities. Consequently, the control over boundary activities does not reside with the project only; the project team's ability to react to and constructively cope with boundary activities initiated from outside of the project might thus be critical to the successful completion of the project. Such "constructive" coping may include guarding and closing project boundaries to retain momentum in project task execution, as well as opening boundaries to outside requests, knowledge, expertise and resources.

It should be noted that there are limitations to our results. A frequent criticism to single-case research studies is their lack of generalizability. However, outcomes from case-based research are usually not statistical, but analytical generalizations [48] based on the case and on theoretical contributions from earlier studies. Theory-informed "rich insight" from singlecase analysis constitutes a valid and adequate form of generalized knowledge [24]. Still, our findings have to be assessed and used with some caution depending on context and conditions: additional studies that add 
variety in contexts and conditions would be beneficial. Our studied project concerned a turnkey solution combining hardware and software modules to a tailored system for an external customer. Clearly projects that provide variety in one of several of these dimensions would be highly worthy of study.

Future research might consider adopting the broader definition of project boundaries employed in this paper. We encourage further studies of how project trajectories are shaped by the everyday dynamics of boundary work. Earlier studies [3] indicate that organizational boundary spanning had considerably greater positive impact on project results than high efficiency and coherence of inside-border project work. This should inspire considerably more research on what happens at the fringes rather than at the "core" of IT projects. For practitioners, this study emphasizes the need for context awareness in the management and governance of IT projects, as well as the need for a broad set of project members to conduct boundary activities throughout the course of a project. The ability to perform boundary work seems to be an essential skill in IT projects.

\section{References}

[1] Alvesson, M., and Sköldberg, K. Towards a reflexive methodology: New vistas for qualitative research. London: Sage, 2000.

[2] Ancona, D., and Bresman, H. Begging, borrowing, and building on ideas from the outside to create pulsed innovation inside teams, in L. Thompson and H.S. Choi, ed., Creativity and innovation in organizational teams, Mahwah, NJ: Lawrence Erlbaum Associates, 2006.

[3] Ancona, D.G., and Caldwell, D.F. Bridging the boundary: External activity and performance in organizational teams. Administrative Science Quarterly, 37, 4, 1992, 634-665.

[4] Ang, S., and Straub, D.W. Production and transaction economies and IS outsourcing: A study of the U.S. Banking industry. MIS Quarterly, 22, 4, 1998, 535-552.

[5] Barki, H., and Hartwick, J. Interpersonal conflict and its management in information systems development. MIS Quarterly, 25, 2, 2001, 195-228.

[6] Bechky, B.A. Gaffers, gofers, and grips: Role-based coordination in temporary organizations. Organization Science, 17, 1, 2006, 3-22.

[7] Bergman, M.; King, J.L.; and Lyytinen, K. Large-scale requirements analysis revisited: The need for understanding the political ecology of requirements engineering. Requirements Engineering, 7, 3, 2002, 152-171.
[8] Carlile, P.R. Transferring, translating, and transforming: An integrative framework for managing knowledge across boundaries. Organization Science, 15, 5, 2004, 555.

[9] Choudhury, V., and Sabherwal, R. Portfolios of control in outsourced software development projects. Information Systems Research, 14, 3, 2003, 291-314.

[10] Dvir, D.; Raz, T.; and Shenhar, A.J. An empirical analysis of the relationship between project planning and project success. International Journal of Project Management, 21, 2, 2003, 89-95.

[11] Eisenhardt, K.M., and Graebner, M.E. Theory building from cases: Opportunities and challenges. Academy of Management Journal, 50, 1, 2007, 25-32.

[12] Ekstedt, E.; Söderholm, A.; and Wirdenius, H. Neoindustrial organising: Renewal by action and knowledge formation in a project-intensive economy. London: Routledge, 1999.

[13] Engwall, M. No project is an island: Linking projects to history and context. Research Policy, 32, 5, 2003, 789-808.

[14] Gann, D.M., and Salter, A.J. Innovation in projectbased, service-enhanced firms: The construction of complex products and systems. Research Policy, 29, 7-8, 2000, 955972.

[15] Gasson, S. A genealogical study of boundary-spanning IS design. European Journal of Information Systems, 15, 1, 2006, 26.

[16] Gieryn, T.F. Cultural boundaries of science: Credibility on the line. Chicago, IL: University of Chicago Press, 1999.

[17] Golden, B.R. Further remarks on retrospective accounts in organizational and strategic management research. Academy of Management Journal, 40, 5, 1997, 1243-1252.

[18] Hall, P. Great planning disasters. Berkeley, CA: University of California Press, 1982.

[19] Hobday, M. The project-based organisation: An ideal form for managing complex products and systems? Research Policy, 29, 7-8, 2000, 871-893.

[20] Katz, R., and Tushman, M.L. A longitudinal study of the effects of boundary spanning supervision on turnover and promotion in research and development. Academy of Management Journal, 26, 3, 1983, 437.

[21] Kimberly, J.R. Issues in the design of longitudinal organizational research. Sociological Methods and Research, 4, 3, 1976, 321-347.

[22] Kirsch, L.J., and Haney, M.H. Requirements determination for common systems: Turning a global vision into a local reality. The Journal of Strategic Information Systems, 15, 2, 2006, 79-104. 
[23] Kreiner, K. In search of relevance: Project management in drifting environments. Scandinavian Journal of Management, 11, 4, 1995, 335-346.

[24] Lee, A.S., and Baskerville, R.L. Generalizing generalizability in information systems research. Information Systems Research, 14, 3, 2003, 221-243.

[25] Levina, N., and Vaast, E. The emergence of boundary spanning competence in practice: Implications for implementation and use of information systems. MIS Quarterly, 29, 2, 2005, 335.

[26] Levina, N., and Vaast, E. Turning a community into a market: A practice perspective on information technology use in boundary spanning. Journal of Management Information Systems, 22, 4, 2006, 13.

[27] Liang, H.; Nilesh, S.; Hu, Q.; and Xue, Y. Assimilation of enterprise systems: The effect of institutional pressures and the mediating role of top management. MIS Quarterly, $31,1,2007,59-87$.

[28] Lindkvist, L. Knowledge communities and knowledge collectivities: A typology of knowledge work in groups. Journal of Management Studies, 42, 6, 2005, 1189-1210.

[29] Lundin, R.A., and Söderholm, A. A theory of the temporary organization. Scandinavian Journal of Management, 11, 4, 1995, 437-455.

[30] Mähring, M. IT project governance. Stockholm: Economic Research Institute (EFI), Stockholm School of Economics, 2002.

[31] Mähring, M., and Keil, M. Information technology project escalation: A process model. Decision Sciences, 39, 2, 2008, 239-272.

[32] Manning, S. Embedding projects in multiple contexts a structuration perspective. International Journal of Project Management, 26, 2008, 30-37.

[33] Markus, M.L., and Keil, M. If we build it, they will come: Designing information systems that users want to use. Sloan Management Review, 35, 4, 1994, 11-25.

[34] Newell, S.; Bresnen, M.; Edelman, L.; Scarbrough, H.; and Swan, J. Sharing knowledge across projects: Limits to ICT-led project review practices. Management Learning, 37, 2, 2006, 167-185.

[35] Pettigrew, A.M. Longitudinal field research on change: Theory and practice. Organization Science, 1, 3, 1990, 267292.

[36] Pettigrew, A.M. What is a processual analysis? Scandinavian Journal of Management, 13, 4, 1997, 337-348.
[37] Pinto, J.K., and Prescott, J.E. Planning and tactical factors in the project implementation process. Journal of Management Studies, 27, 3, 1990, 305-327.

[38] Pouloudi, A., and Whitley, E.A. Stakeholder identification in inter-organizational systems: Insights for drug use management systems. European Journal of Information Systems, 6, 1, 1997, 1-14.

[39] Romanelli, E., and Tushman, M.L. Organizational transformation as punctuated equilibrium: An empirical test. Academy of Management Journal, 37, 5, 1994, 1141-1166.

[40] Sahlin-Andersson, K. Project management as boundary work, in Kerstin Sahlin-Andersson and Anders Söderholm, ed., Beyond project management: New perspectives on the temporary - permanent dilemma, Copenhagen: Liber, 2002, 241-260.

[41] Scarbrough, H.; Swan, J.; Laurent, S.; Bresnen, M.; Edelman, L.; and Newell, S. Project-based learning and the role of learning boundaries. Organization Studies, 25, 9, 2004, 1579-1600.

[42] Stinchcombe, A.L. Contracts as hierarchical documents", in A.L. Stinchcombe and C.A. Heimer, ed., Organization theory and project management: Administering uncertainty in Norwegian offshore oil, Oslo: Norwegian University Press, 1985.

[43] Sydow, J.; Lindkvist, L.; and DeFillippi, R. Projectbased organization, embeddedness and repositories of knowledge: Editorial. Organization Studies, 25, 9, 2004, 1475 .

[44] Turner, J.R., and Müller, R. On the nature of the project as a temporary organization. International Journal of Project Management, 21, 1, 2003, 1-8.

[45] Tushman, M.L., and Scanlan, T.J. Characteristics and external orientations of boundary spanning individuals. Academy of Management Journal, 24, 1, 1981, 83.

[46] Van de Ven, A.H., and Huber, G.P. Longitudinal field research methods for studying processes of organizational change. Organization Science, 1, 3, 1990, 213-219.

[47] Yakura, E.K. Charting time: Timelines as temporal boundary objects. Academy of Management Journal, 45, 5, 2002, 956 .

[48] Yin, R.K. Case study research: Design and methods. Third ed., Thousand Oaks, CA: Sage Publications, 2003. 